\title{
Inter-relation of Sylvatic and Domestic Transmission of Trypanosoma cruzi in Areas with and without Domestic Vectorial Transmission in Minas Gerais, Brazil
}

\author{
L Diotaiuti, AS Pereira ${ }^{*}$, CF Loiola** ${ }^{*}$ A] Fernandes ${ }^{* *}$, JC Schofield***, \\ JP Dujardin ${ }^{* * * *}$, JCP Dias ${ }^{* *}$, E Chiari
}

\begin{abstract}
Departamento de Parasitologia *Departamento de Bioquímica, ICB, UFMG, Caixa Postal 2486, 31270-901 Belo Horizonte, MG, Brasil ${ }^{* *}$ Centro de Pesquisas René Rachou-FIOCRUZ, Caixa Postal 1743, 30190-002 Belo Horizonte, MG, Brasil ${ }^{* * *}$ London School of Tropical Medicine and Hygiene, WC1 E7HT, London, UK **** ORSTOM, BP 5445, 34032 Montpellier, France
\end{abstract}

During the period 1980-1986, we captured triatomine bugs and mammalian reservoir hosts from sylvatic and domestic situations in different municipalities of the State of Minas Gerais. Trypanosoma cruzi was isolated from captured bugs, mammals and patients. After cultivation in LIT medium, the electrophoretic enzyme profiles were determined. We obtained a total of 32 parasite isolates from regions with active domestic transmission, and 24 isolates from areas under control. For the first areas the results suggest introduction of $\mathrm{T}$. cruzi from sylvatic habitats, through incursion of infected opossums and/or sylvatic $\mathrm{T}$. sordida, which appears to have given rise to at least one acute human infection. Of particular interest is the finding of sylvatic opossums and $a \mathrm{~T}$. sordida nymph infected with $Z B$, that could indicate return of parasites from chronic human infections to sylvatic transmission cycles. For the areas under control we also interpret the results as interaction between sylvatic and domestic cycles of transmission, here through the invasion of houses by bugs carrying the ZI zymodeme from the sylvatic environment. The Multivariate Correspondence Analysis gives a spatial description between the different parasite isolates and confirms the existence of a bridge in the opposite direction in the region with active vectorial transmission including the exporting of $Z 2$ through the peridomestic environment into the sylvatic cycle. For the other areas this bridge corresponds especially to Panstrongylus megistus, importing $\mathrm{Zl}$ into the domestic environment.

Key words: Trypanosoma cruzi - isoenzyme - Chagas' disease

Enzymatic variation in Trypanosoma cruzi seems largely due to clonal expansion of the parasite under different conditions of selection (Tibayrenc \& Ayala 1988). However, the electrophoretic isoenzyme patterns can be grouped into major zymodemes that are each associated with particular epidemiological situations (Miles 1983). In Brazil for example, zymodemes $\mathrm{Zl}$ and $\mathrm{Z3}$ are principally associated with sylvatic transmission (Z1 mainly with opossums, and Z3 mainly with armadillos) (Miles 1985), while $Z 2$ has been mainly isolated from patients in the chronic phase of Chagas' disease, particularly in the Southern and Central regions (Romanha 1982, Miles 1983 . Luquetti ct al. 1986), which correspond to the principal Triatoma infestans distribution area in the country. The association $T$. infestans/Z2 zymodeme becomes weaker in the North and Northern re-

Received 13 September 1994

Accepted 18 April 1995 gions of the country, where the $\mathrm{Z} 2$ zymodeme is episodic in the State of Ceará (Alencar 1987) and absent in Amazonia and Venezuela (Miles 1985). Mixture areas in the State of Bahia (Barrett et al. $1980)$ are probably explained by the close distribution of $T$. infestans with the strictly domestic Panstrongylus megistus.

Studying chagasic patients from Bambui, Minas Gerais, Brazil, Romanha (1982) classified the parasite isolates in four zymodemes, ZA, ZB, $Z C$, and $Z D$. $Z A$ is equivalent to $Z 2$ of Miles et al. (1977), while $Z B$ and $Z C$ are distinct (Bogliolo et al. 1986) and ZD represented a mixture of parasites with patterns $Z A$ and $Z C$. Romanha's study showed a predominance of ZA (or Z2) amongst the isolates from humans. Different papers confirm the great homogeneity of the parasites in the sylvatic environment, showing prevalently $\mathrm{Z} 1$ isozyme profiles (Miles et al. 1981, Póvoa et al. 1984, Fernandes et al. 1991, Steindel et al. 1993). The similarity of banding patterns between para- 
sites from a fatal acute case from the north of the State of Minas Gerais and two isolates from opossums led Romanha (1982) to suggest that T. cruzi from sylvatic transmission cycles had been recently introduced into the domestic situation. Use of isozyme profiles as epidemiological markers is a helpful tool for examining the relationship between sylvatic and domestic transmission cycles of $T$. cruzi. The technique was developed after $T$. infestans had become established as the principle domestic vector in Brazil (Schofield 1988), but before major control interventions against this vector had been carried out over the greater part of the country (Dias 1987). As a result, the initial interpretations of association between $Z 1$ zymodeme with the sylvatic cycle, and $Z 2$ zymodeme with human disease, although representing considerable simplification, for the southern and central Brazil probably does reflect a generalised distinction between domestic transmission involving $T$. infestans and sylvatic transmission involving other species of Triatominae. T. infestans is thought to have invaded Brazil since the turn of this century, mainly by passive dispersal in association with human migrations (Schofield 1988). Its origins seem to have been in the Cochabamba region of Bolivia (Dujardin et al. 1987), and it may have been responsible for the spread of the zymodeme $\mathrm{Z} 2$ of $T$. cruzi from that region, introducing it into Brazil where the predominant zymodeme had previously been $Z 1$. The association between the rymodeme $Z 2$ and $P$. megistus in the State of Bahia reinforces the correlation of this pattern with the domestic cycle of 7 . cruzi whete this triatomine accomplishes the epidemiological behaviour of T. infestans in Reconcavo Bahiano (Barrett et al. 1980). In at least one case, introduction of T? infestans into northeastern Brazil was associated with an outbreak of $T$. cruzi transmission involving zymodeme Z2 (Barrett et al. 1980). In Brazil, there has been considerable success in interrupting domestic cycles of $T$. cruz $i$ transmission by eliminating domestic species of the triatomine bug vectors (Dias 1987). However, there is an ever present risk of reinvasion of treated houses by sylvatic species of Triatominae, which may lead to important changes in the epidemiology of Chagas' disease in the treated regions. For example, after climination of $T$. infestans as the major domestic vector in parts of the State of Minas Gerais, two other triatomine species - $T$. sordida and P. megistus - have become more frequently reported from the rural houses, representing reinvasion from sylvatic ecotopes (Diotaiuti et al. 1993). The aim of the present study is therefore to compare the epidemiological patterns of $T$. cruzi transmission in regions of Minas Gerais where the vectorial transmission of Chagas' disease is still occurring, and regions where this transmission was interrupted.

\section{MATERIALS AND METHODS}

During the period 1980-1986, we captured triatomine bugs and mammalian reservoir hosts from sylvatic and domestic situations in different municipalities of the State of Minas Gerais, East region of Brazil. This period covered the start and conclusion of a major national control campaign against $T$. infestans, the principal domestic vector of $T$. cruzi in the region (Dias 1987).

T. cruzi was isolated from captured bugs by inoculation of bugs faeces into mice. Xenodiagnosis using laboratory-bred $T$. infestans nymphs was carried out on the captured mammals, and faeces from these bugs were also inoculated into mice. Using the same procedure, we also obtained parasite isolates from two chronic-phase patients from a region where no Chagas' disease transmission had been reported for many years, and from one acute-phase patient from a region where vector transmission is still active.

Parasites from the inoculated mice were cultivated in LIT medium (Camargo 1964), and their electrophoretic enzyme profiles determined using the methods of Romanha (1982). Each enzyme testplate included control samples representing $\mathrm{Z1}, \mathrm{Z2}$ and $Z 3$ (Miles et al. 1977), and control samples of ZA, ZB, ZC and ZD (Romanha 1982). Six enzymes were developed: ALAT, (EC 2.6.1.2), ASAT (EC 2.6.1.1), GPI (EC 5.3.1.9), PGM (EC 2.7.5.1), G6PD (EC 1.1.1.49) and ME (EC 1.1.40).

Data were considered by area, with or without actual transmission (Tables I, II), and were analyzed by a Multiple Correspondence Analysis (Thioulouse 1990). The factor maps from this analysis are presented for the two first factor coordinates (Figs 1,2), corresponding to Tables I and II, respectively.

\section{RESULTS AND DISCUSSION}

We obtained a total of 32 parasite isolates from regions with actual active domestic transmission, and 24 isolates from areas under control. The zymodeme profiles all corresponded to $\mathrm{ZB}$ and $\mathrm{ZC}$ of Romanha (1982), or Z1 and Z2 of Miles et al. (1977) (Tables I, II).

In areas with actual active domestic transmission we found $\mathrm{Zl}, \mathrm{Z2}$ and $\mathrm{ZB}$ rymodemes of $T$. cruzi (Table I). Most $T$. infestans had Z2 or ZB, which are considered characteristic of human infections in southern and central Brazil (Miles et al. 1977, Romanha 1982, Luquetti et al. 1986). However, some of the T. infestans, most $T$. sordida and most opossums showed $\mathrm{Zl}$ zymodeme which is generally considered characteristic of sylvatic 


\section{TABLE I}

Local of capture, origin and electrophoretic isoenzyme patterns of Trypanosoma cruzi isolates from human patients, triatomines and reservoirs in areas with active vectorial transmission of Chagas' disease, in the State of Minas Gerais, Brazil

\begin{tabular}{|c|c|c|c|c|}
\hline Isolate number & Municipality & Local of capture & Origin & Zymodeme \\
\hline 1 & Itacarambi & domestic & T. infestans & $\mathrm{B}$ \\
\hline 2 & Itacarambi & domestic & T. infestans & $\mathrm{Zl}$ \\
\hline 3 & Itacarambi & domestic & T. infestans & $\mathrm{Zl}$ \\
\hline 4 & Itacarambi & domestic & T. infestans & $\mathrm{Zl}$ \\
\hline 5 & Itacarambi & - & Human/acute & $\mathrm{Zl}$ \\
\hline 6 & Itacarambi & domestic & T. infestans & $\mathrm{Z} 1$ \\
\hline 7 & Itacarambi & peridomestic & T. sordida & $\mathrm{Z1}$ \\
\hline 8 & Manga & domestic & T. infestans & B \\
\hline 9 & Manga & domestic & T. infestans & B \\
\hline 10 & Manga & domestic & T. infestans & B \\
\hline 11 & Montalvânia & peridomestic & T. sordida & $\mathrm{B}$ \\
\hline 12 & Montalvânia & domestic & T. sordida & $\mathrm{Z1}$ \\
\hline 13 & Mato Verde & peridomestic & T. sordida & $\mathrm{Z1}$ \\
\hline 14 & Mato Verde & domestic & T. infestans & $\mathrm{B}$ \\
\hline 15 & Mato Verde & sylvatic & T. sordida & $\mathrm{Zl}$ \\
\hline 16 & Mato Verde & sylvatic & D. albiventris & $B+Z 1$ \\
\hline 17 & Mato Verde & sylvatic & D. albiventris & $B+Z 1$ \\
\hline 18 & Mato Verde & sylvatic & T. sordida & B \\
\hline 19 & Mato Verde & sylvatic & D. albiventris & $\mathrm{Zl}$ \\
\hline 20 & Mato Verde & sylvatic & D. albiventris & $\mathrm{Z1}$ \\
\hline 21 & Mato Verde & domestic & $T$. infestans & $\mathrm{Z} 2$ \\
\hline 22 & Mato Verde & domestic & T. infestans & $\mathrm{B}$ \\
\hline 23 & Mato Verde & sylvatic & T. sordida & $\mathrm{Z} 1$ \\
\hline 24 & Mato Verde & peridomestic & D. albiventris & $\mathrm{Z} 1$ \\
\hline 25 & Mato Verde & sylvatic & D. albiventris & $\mathrm{Zl}$ \\
\hline 26 & Mato Verde & sylvatic & D. albiventris & $\mathrm{Z1}$ \\
\hline 27 & Mato Verde & sylvatic & D. albiventris & $\mathrm{Zl}$ \\
\hline 28 & Mato Verde & sylvatic & D. albiventris & $\mathrm{Z1}$ \\
\hline 29 & Mato Verde & sylvatic & D. albiventris & $\mathrm{Zl}$ \\
\hline 30 & Mato Verde & sylvatic & D. albiventris & $\mathrm{Zl}$ \\
\hline 31 & Mato Verde & sylvatic & D. albiventris & $\mathrm{Z} 1$ \\
\hline 32 & Mato Verde & sylvatic & D. albiventris & $\mathrm{Z1}$ \\
\hline
\end{tabular}

T. cruzi. This strongly suggests introduction of $T$, cruzi from sylvatic habitats, through incursion of infected opossums and/or sylvatic $T$. sordida, and appears to have given rise to at least one acute (ie. recent) human infection (Table I). Of particular interest here, however, is the finding of sylvatic opossums and a $T$. sordida nymph infected with ZB zymodeme of $T$. cruzi. These were captured in a wood about $50 \mathrm{~m}$ from the nearest house (where at least one inhabitant was seropositive for $T$. cruzi) and could possibly indicate return of parasites from chronic human infections to sylvatic transmission cycles.

The areas under control represent regions where vectorial transmission of $T$. cruzi was previously high, but now do not record the presence of triatomine colonization within the houses. Nev- crtheless, some autochthonous species of Triatominae are found in sylvatic ecotopes and, occasionally, inside houses. In these regions (Table II) we verified the presence of $Z 1$ in sylvatic Triatominae and opossums, and in most of the bugs ( $P$. megistus) captured in and around houses. Two patients with chronic infections showed $\mathrm{Z} 2$ isoenzyme profiles, and four of the $P$. megistus showed $\mathrm{ZB}$ or $\mathrm{Z} 2$ profiles which are more usually associated with chronic human disease. Again therefore, we interpret these results to indicate interaction between sylvatic and domestic cycles of transmission. Here, it would appear that invasion of houses by otherwise sylvatic bugs can not only introduce $Z 1$ into the domestic environment, but these bugs can also reconstitute domestic transmission of $Z 2$. However, Tibayrenc et al. $(1986,1990)$ have pre- 


\section{TABLE II}

Local of capture, origin and electrophoretic isoenzyme patterns of Trypansoma cruzi isolates from human patients, triatomines and reservoirs in areas without active vectorial transmission of Chagas' disease, in the state of Minas Gerais, Brazil

\begin{tabular}{|c|c|c|c|c|}
\hline Isolate number & Municipality & Local of capture & Origin & Zymodeme \\
\hline 1 & Caeté & sylvatic & D. albiventris & $\mathrm{Z1}$ \\
\hline 2 & Patos de Minas & domestic & $P$. megistus & $\mathrm{Z2}$ \\
\hline 3 & Patos de Minas & - & Human/cronic & $\mathrm{Z} 2$ \\
\hline 4 & Patos de Minas & domestic & $P$. megistus & $\mathrm{Z1}$ \\
\hline 5 & Patos de Minas & domestic & P. megistus & Z1 \\
\hline 6 & Patos de Minas & peridomestic & P. megistus & $\mathrm{Z} 1$ \\
\hline 7 & Virgem da Lapa & domestic & P. megistus & $\mathrm{Z} 2$ \\
\hline 8 & Virgem da Lapa & domestic & T. vitticeps & $\mathrm{C}$ \\
\hline 9 & Jaboticatubas & - & Human/cronic & $\mathrm{Z} 2$ \\
\hline 10 & Contagem & domestic & P. megistus & $\mathrm{Z1}$ \\
\hline 11 & Betim & peridomestic & P. megistus & $\mathrm{Z1}$ \\
\hline 12 & Betim & peridomestic & P. megistus & $\mathrm{Zl}$ \\
\hline 13 & Ibirité & domestic & P. megistus & $\mathrm{B}$ \\
\hline 14 & Minas Novas & domestic & P. megistus & B \\
\hline 15 & Guaranésia & domestic & P. megistus & $B$ \\
\hline 16 & Guaranésia & peridomestic & P. megistus & $\mathrm{Z1}$ \\
\hline 17 & Monte Belo & peridomestic & P. megistus & $\mathrm{Z1}$ \\
\hline 18 & Brumadinho & peridomestic & P. megistus & $\mathrm{Zl}$ \\
\hline 19 & C. Mato Dentro & domestic & P. megistus & $\mathrm{Z} 2$ \\
\hline 20 & Itapagipe & domestic & P. megistus & $\mathrm{Z} 2$ \\
\hline 21 & Itapagipe & sylvatic & R. neglectus & Z1 \\
\hline 22 & Itapagipe & sylvatic & P. megistus & Z1 \\
\hline 23 & Itapagipe & sylvatic & D. albiventris & Z1 \\
\hline 24 & Itapagipe & sylvatic & D. albiventris & $\mathrm{Z1}$ \\
\hline
\end{tabular}

viously noted the presence of mixed zymodemes in infections of individual humans and triatomines, while Finlay and Dvorak (1987) have modelled the rapid overgrowth of fast-growing $T$. cruzi clones during the passage of new isolates. We cannot therefore exclude the possibility of loss of some biological clones during our passage of isolates through cultures and mice, such that $Z 2$ zymodeme for example, may have been present among some of the primary isolates subsequently identified as Zl zymodeme.

The Multivariate Correspondence Analysis helps to illustrate the apparent interactions between sylvatic and domestic transmission in the two areas, by giving a spatial description of correspondence between the different parasite isolates. For the areas with actual active transmission, the analysis shows eight grouping of parasite isolates (Fig. 1). Groups $a$ and $b$ correspond to all the domestic isolates from $T$. infestans and from a human acute case, while groups $c$ and $d$ correspond to all the sylvatic isolates from Didelphis. These groups are clearly distinguished from each other by the $y$ factor axis, and by the $x$ factor axis from the remaining groups which correspond to isolates from $T$. sordida from sylvatic, peridomestic and domestic habitats, together with the single peridomestic isolate from Didelphis. The implication of this correspondence is that $T$. sordida is acting as an effective brigde between sylvatic and domestic habitats, importing parasites of zymodeme $Z 1$ from the sylvatic cycle to the domestic environment. However, the position of groups $d$ and $h$ could imply also a bridge in the opposite direction, exporting Z2 zymodeme of $T$. cruzi through the peridomestic environment into the sylvatic cycle.

For the areas under transmission control, the same analysis drew fewer groups, but again illustrated a correspondence between the parasite isolates in accordance with their domestic, peridomestic or sylvatic origins (Fig. 2). Groups $a$ and $b$ correspond to domestic isolates showing $\mathrm{ZB}, \mathrm{Z1}$ and $Z 2$ zymodemes of $T$. cruzi, group $c$ corresponds to peridomestic $\mathrm{Zl}$ zymodeme isolates, and group $d$ corresponds to sylvatic $Z 1$ zymodeme isolates. Again the distribution of parasite isolates within these groups implies a bridge, this time by $P$. 


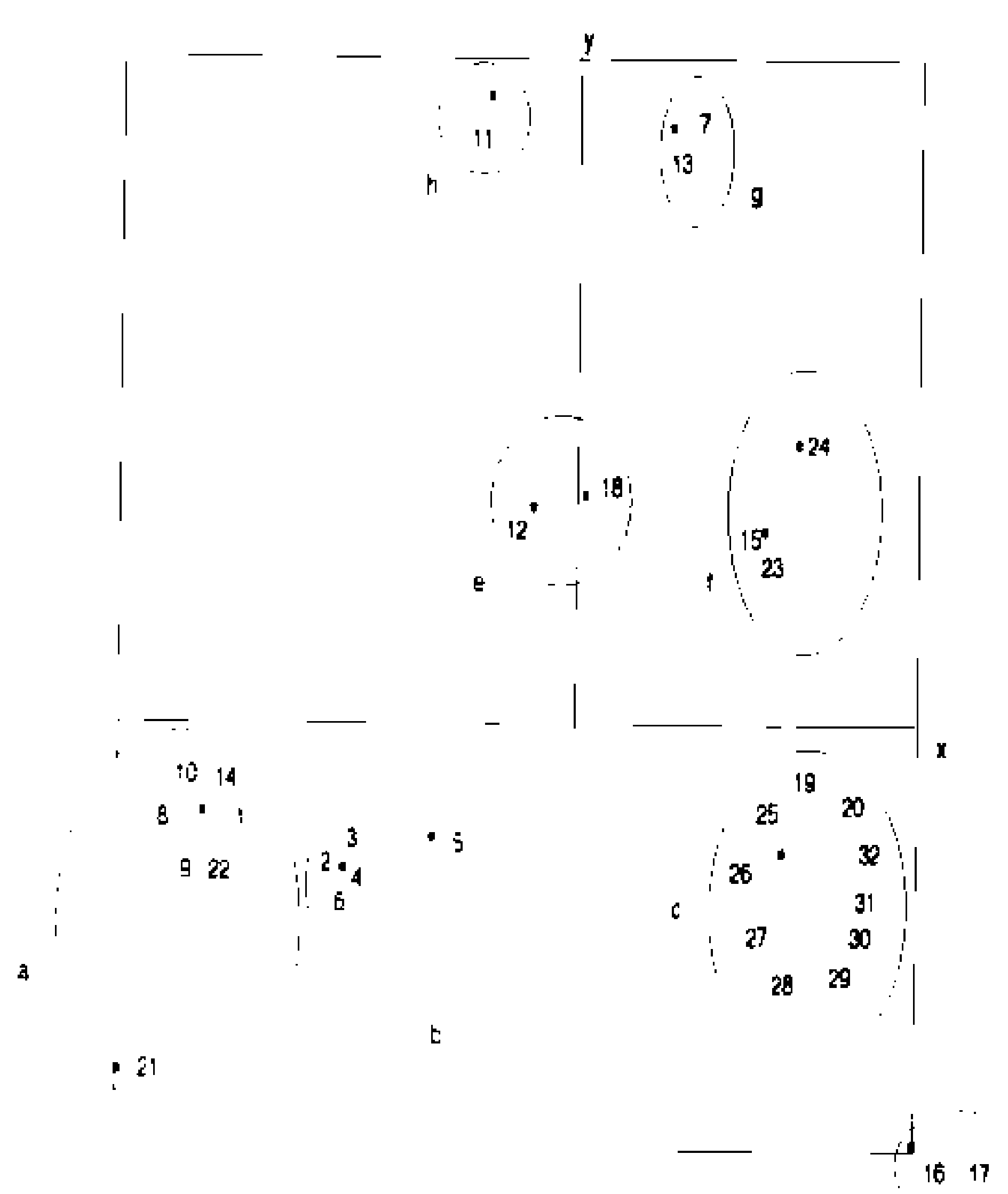

Fig. 1: factor map of the multiple correspondence analysis performed on Table I. The two first (out of 9) factor coordinates are the $x$ and $y$ axis, respectively, and represent $43 \%$ of the total variability. Domestic, peridomestic and sylvatic transmissions are separated mainly by the first axis $(r=0.81)$, while the vectors and zymodemes were more correlated to the second axis ( $r=0.97$ and 0.88 , respectively). $r$ is the correlation between the variable and the factor.

megistus, importing $\mathrm{Z} 1$ zymodeme into the domestic environment.

In a few areas of Brazil - especially in the municipality of Bambui, Minas Gerais - control of $T$. infestans has been effected for many years. In much of the country, however, control of this vector has only been effective since 1983 (Dias 1987). It would appear that control of this domestic vector can significantly reduce the transmission of $T$. cruzi Z2 zymodeme. However, the reinvasion of houses by other species of Triatominae from sylvatic environments can initiate domestic transmission of Zl zymodeme and may reconstitute domestic transmission of Z2 zymodeme. Opossums, which are often infected with $T$. cruzi, appear to play an important role in introducing $Z 1$ pattern into domestic and peridomestic environments. This fact emphasises the need for continued vigilance of controlled areas in order to avoid colonization of houses by the bugs and opossums which are the main components of the sylvatic (Z1 zymodeme) transmission cycle of $T$. cruzi.

\section{REFERENCES}

Alencar JE 1987. História natural da doença de Chagas no Estado do Ceará. Imprensa Universitária da UFC, Fortaleza, $341 \mathrm{pp}$

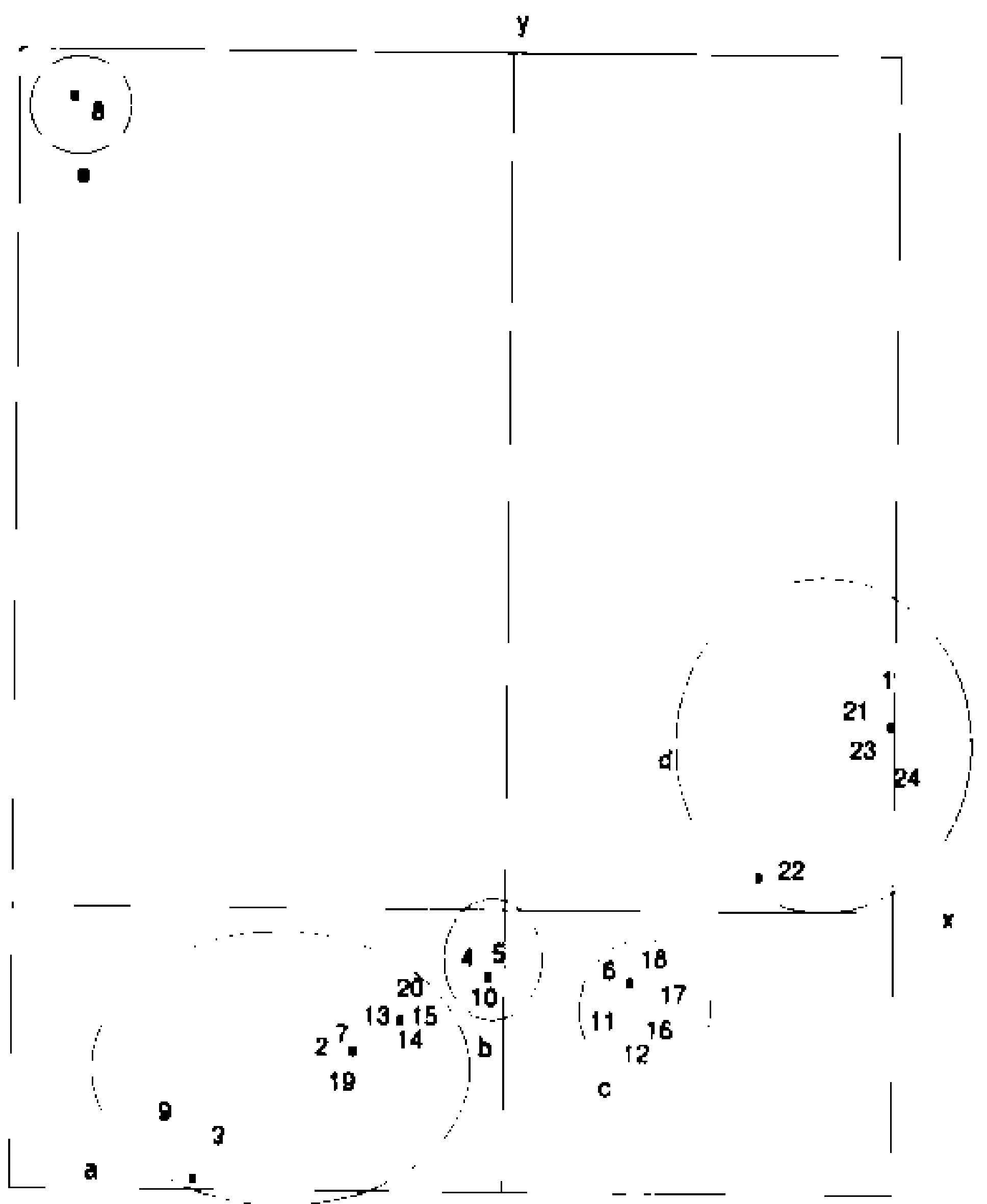

Fig. 2: factor map of the multiple correspondence analysis performed on Table II. The two first (out of 8 ) factor coordinates are the $x$ and $y$ axis, respectively, and represent $49 \%$ of the total variability. Domestic, peridomestic and sylvatic transmissions, as well as the different vectors, are separated mainly by the first axis $(r=0.87$ and 0.93 , respectively), while the zymodemes were more correlated to the second axis $(r=0.60)$. $r$ is the correlation between the variable and the factor.

Barrett TV, Hoff RH, Mott KE, Miles MA, Godfrey DG, Teixeira R, Souza JAA, Sherlock I 1980. Epidemiological aspects of three Trypanosoma cruzi zymodemes in Bahia State, Brazil. Trans $R$ Soc Trop Med Hyg 74: 84-90.

Bogliolo AR, Chiari E, Silva-Pereira RO, Silva-Pereira A 1986. Comparative study of Trypanosoma cruzi enzyme polymorphirms in South America. Braz J Med Biol Research 19: 673-683.

Camargo EP 1964. Growth and differenciation in Trypanosoma cruzi. I. Origin of metacyclic trypanosomes in liquid media. Rev Inst Med Trop de São Paulo 6: 93-100.

Dias JCP 1987. Control of Chagas disease in Brazil. Parasitol Today 3: 336-341.

Diotaiuti L, Loiola CF, Falcão PL, Dias JCP 1993. The ecology of Triatoma sordida in natural environments in two different regions of the State of Minas Gerais, Brazil. Rev Inst Med Trop São Paulo 35: 237-246

Dujardin JP, Tibayrenc $M$, Venegas $E$, Maldonado $L$, Desjeux P, Ayala J 1987. Isozyme evidence of lack of speciation between wild and domestic Triatoma infestans (Heteroptera: Reduviidae) in Bolivia. $J$ Med Ent 24: 1-40.

Fernandes AJ, Chiari E, Rodrigues RR, Dias JCP, Romanha AJ 1991. The importance of the opossum (Didelphis albiventris) as a reservoir for Trypa- 
nosoma cruzi in Bambuí, Minas Gerais State. Mem Inst Oswaldo Cruz 86: 81-85.

Finlay RW, Dvorak JA 1987. Trypanosoma cruzi: analysis of the population dynamics of heterogenous mixtures. J Protoz $34: 409-415$.

Luquetti AO, Miles MA, Rassi A, Rezende JM, Souza AA, Póvoa MM, Rodrigues I 1986. Trypanosoma cruzi: zymodemes associated with acute and chronic Chagas' disease in Central Brazil. Trans R Soc Trop Med Hyg 80:462-470.

Miles MA 1983. The epidemiology of South American Trypanosomiasis - biochemical and immunological approaches and their relevance to control. Trans $R$ Soc Trop Med Hyg 7: 5-23.

Miles MA 1985. Isoenzyme characterization. Rev Soc Brasil Med Trop 18: 53-59.

Miles MA, Toye PJ, Oswald SC, Godfrey DG 1977. The identification by isoenzyme patterns of two distinct strain-groups of Trypanosoma cruzi circulating independently in a rural area of Brazil. Trans $R$ Soc Trop Med Hyg 71: 217-225.

Miles MA, Povoa MM, Souza AA, Lainson R, Shaw JJ, Ketteridge DS 1981. Chagas disease in the Amazon Basis. II. The distribution of Trypanosoma cruzi zymodeme 1 and 3 in Pará state, North Brazil. Trans R Soc Trop Med Hyg 75: 667-674.

Póvoa MM, Souza AA, Naiff RD, Arias JR, Naiff MF, Biancardi CB, Miles MA 1984. Chagas disease in the Amazon Basis. IV. Host records of Trypanosoma cruzi zymodemes in the State of Amazonas and Rondônia, Brazil. Ann Trop Med Parasit 78: 479-487.
Romanha AJ 1982. Heterogeneidade isoenzimática em Trypanosoma cruzi. PHD Thesis. Universidade Federal de Minas Gerais, Belo Horizonte, Brazil, 110 pp.

Schofield CJ 1988. The bioystematics of Triatominae. In Biosystematics of haematophagous Insects. p. 284-312 MW Service, Systematic Association Special Vol 37.

Steindel M, Dias Neto E, Menezes CLP, Romanha AJ, Simpson AJG 1993. Random amplified polymorphic DNA analysis of Trypanosoma cruzi strains. Mol Bioch Paras 60 : 71-80.

Thiouslouse J 1990. MacMul and GraphMu: two macintosh programs for the display and analysis of Mltivariate data. Computers and Geoscience 16: 1235-1240.

Tibayrenc M, Ayala FJ 1988. Isoenzyme variability in Trypanosoma cruzi the agent of Chagas disease: genetical, taxonomical and epidemiological significance. Evolution $42: 277-292$.

Tibayrenc M, Hoffmann A, Poch O, Echalar L, Le Pont F, Lemesre L, Desjeux P, Ayala FJ 1986. Additional data on Trypanosoma cruzi isoenzyme strains encountered in Bolivian domestic transmission cycles. Trans R Soc Trop Med Hyg 80: 442-447.

Tibayrenc M, Kjellberg F, Ayala FJ 1990. A clonal theory of parasitic protoza: the population strutures of $E n$ tamoeba, Giardia, Leishmania, Naegleria, Plasmodium, Trichonomas, and Trypanosoma and their medical and taxonomical consequences. Evolution 87: 2414-2418. 